\title{
Non-Invasive Cancer Detection
}

National Cancer Institute

\section{Source}

National Cancer Institute. Non-Invasive Cancer Detection. NCI Thesaurus. Code C16107.

Methods of detection which do not require penetration of the body or body openings. 